\title{
Recuperação e Reforço de Sistema Estrutural com Placas Pré-Moldadas Alveolares
}

\author{
PANTOJA, João da Costa ${ }^{1}$ \\ NARVAEZ, Nathaly Sarasty ${ }^{2}$ \\ PINTO, Ricardo Luiz Ferreira ${ }^{3}$ \\ SANTANA, Thayane ${ }^{4}$ \\ ${ }^{1}$ Universidade de Brasília, Brasil. joaocpantoja@gmail.com \\ ${ }^{2}$ Centro Universitário de Brasília, Brasil. nathalysarasty@hotmail.com \\ ${ }^{3}$ Centro Universitário de Brasília, Brasil. ricardo.sol@terra.com.br \\ ${ }^{4}$ Centro Universitário de Brasília, Brasil. thayane.santana@hotmail.com
}

\begin{abstract}
Resumo
O objetivo deste estudo foi avaliar a estrutura de uma casa de dois pavimentos, cujo sistema estrutural é constituído por placas pré-moldadas alveolares. As placas foram utilizadas de forma errônea durante a construção, fazendo com que o projeto apresentasse diversos problemas antes mesmo do término da construção. Para a avaliação de segurança da mesma, foram realizadas vistorias à construção e análise de patologias presentes nos elementos estruturais: fundação, vigas, pilares, e pré-moldados. Foram constatadas diversas patologias causadas por falta de projeto estrutural, erros de execução e defeitos de fábrica nos elementos analisados. Para conter e reparar os diversos problemas detectados foi elaborado um projeto de reforço e recuperação.
\end{abstract}

Palavras-Chave: estrutura, pré-moldados, execução, patologia.

\begin{abstract}
The aim of this study was to evaluate the structure of a two floors house, made in alveolar precast slabs, which was wrongly executed, and then presented several problems even before the completion of construction. For the safety assessment of the same, visits of the construction and analysis of runtime errors and pathologies were performed on structural elements: foundation, beams, colu$\mathrm{mns}$, slabs and precast. Execution errors, pathologies and factory defects were observed in the analyzed elements. To contain and repair the various problems encountered was made a project of reinforcement.
\end{abstract}

Key Words: structure, precast, execution, pathology. 


\section{Introdução}

O uso de pré-moldados na construção é sinônimo de rapidez, economia, eficiência, desempenho técnico, segurança, condições favoráveis de trabalho e de sustentabilidade, quesitos bastante atrativos, já que, as obras civis estão frequentemente associadas, a atraso, alto custo, sujeira e resíduos. Logo, com todas estas vantagens, a utilização de prémoldados tem ganhado espaço na construção civil. Os pré-moldados são fabricados fora da obra, o que diminui a utilização de madeira para formas e, consequentemente, a sujeira e resíduos. Para garantir os benefícios, as peças pré-moldadas exigem mão de obra especializada e maior controle tecnológico.

Na residência em estudo, o sistema estrutural escolhido está constituído principalmente por elementos pré-moldados, utilizados tanto para lajes quanto para paredes estruturais. Existem também regiões da casa com sistema estrutural viga-pilar como a garagem.

O principal inconveniente neste caso, é a falta de um projeto estrutural que defina o uso correto dos elementos pré-moldados a fim de permitir a realização do projeto arquitetônico existente, verificando a capacidade resistente dos elementos utilizados. Apenas uma planta de montagem de paredes e lajes foi fornecida.

Decorrente da falta de projeto estrutural, algumas patologias típicas começaram a ser evidenciadas rapidamente no projeto ainda em construção. $O$ que levou a necessidade de colocar um sistema de escoramentos que garantisse a segurança dos operários e da estrutura, evitando que os Estados Limites Últimos fossem alcançados.

Com o prédio escorado e sem a possiblidade de continuar os trabalhos por falta de segurança, foram contratados os serviços de um especialista em estruturas a fim de realizar um laudo e posteriormente caso fosse necessário, um projeto de reforço e recuperação de estruturas.

\section{Execução de laudo técnico}

Inicialmente, foi realizado um laudo para a avaliação da estrutura da residência. A casa é composta por dois níveis, sendo térreo e primeiro pavimento. Abaixo as Figuras de 1 a 3 mostram as fachadas da casa.
Figura 1: Fachada frontal.

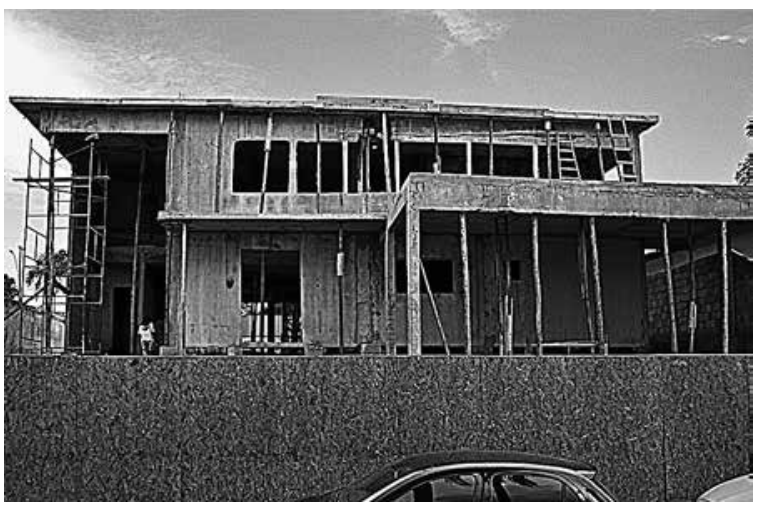

Figura 2: Fachada posterior.

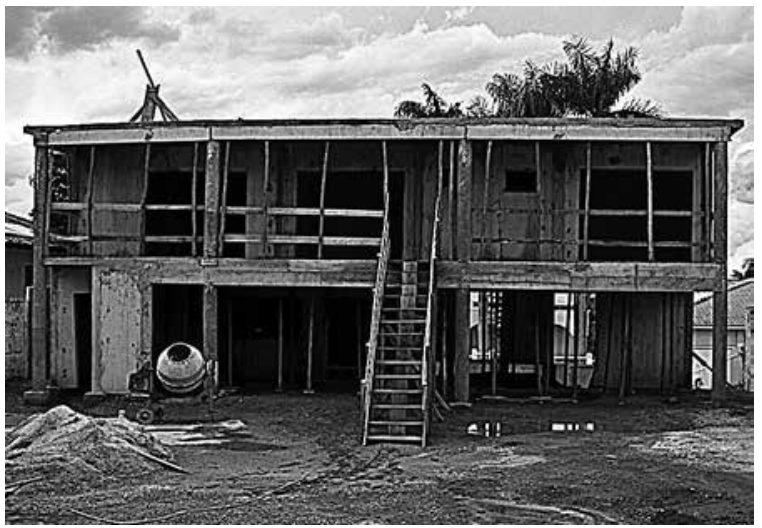

Figura 3: Lateral direita.

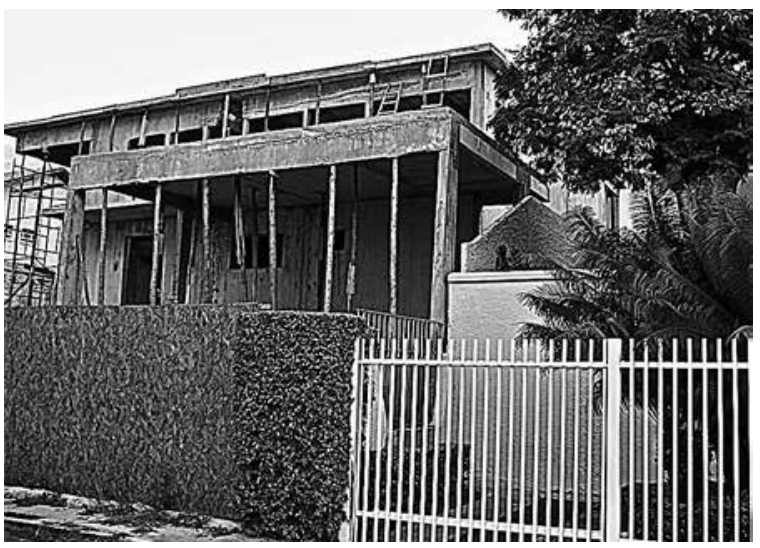

\subsection{Vistoria no local}

\subsubsection{Fundações}

O projeto de fundações para esta residência consta de 25 bloco-estacas, sendo: onze estacas com $30 \mathrm{~cm}$ de diâmetro, cinco estacas com 40 $\mathrm{cm}$ de diâmetro, quatro estacas com $50 \mathrm{~cm}$ de diâmetro, duas estacas com $60 \mathrm{~cm}$ de diâmetro e três tubulões de $60 \mathrm{~cm}$ de diâmetro, mostrado na Figura 4. 
Figura 4: Projeto de fundações.

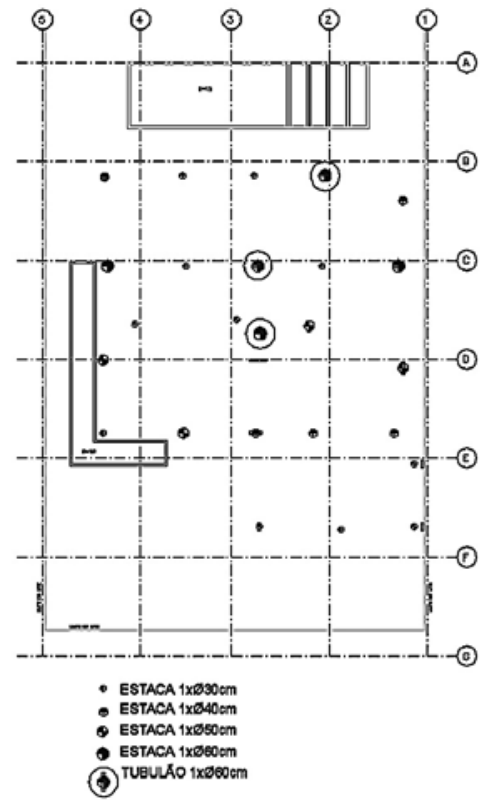

Para verificar o tipo de fundação executada e suas dimensões, foram feitos dois poços de visita na obra, suas localizações são mostradas na Figura 5, e o poço de visita na Figura 6.

Figura 5: Localização dos poços de visitas.

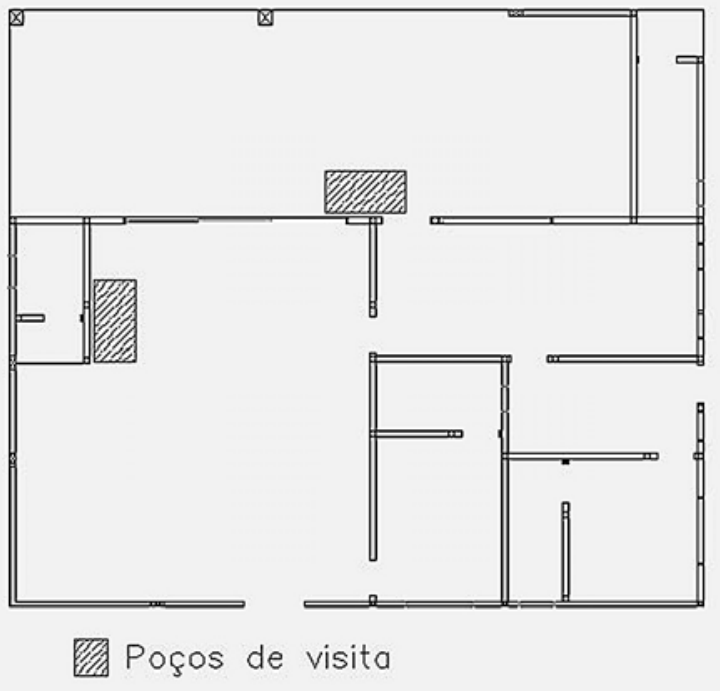

Figura 6: Poço de visita.

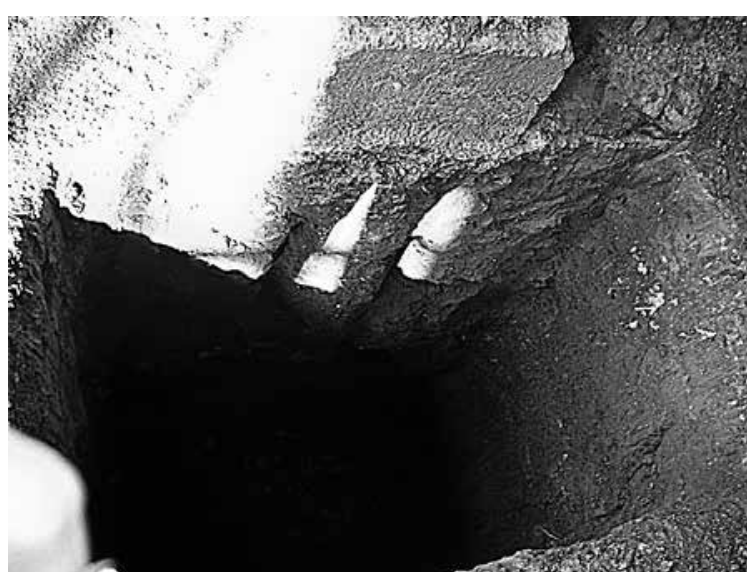

De acordo com o que foi vistoriado na obra, para receber os carregamentos das paredes estruturais foram executados blocos de fundação cujas dimensões são: $45 \mathrm{~cm} x$ $45 \mathrm{~cm} \times 60 \mathrm{~cm}$.

Foi constatado através dos poços de inspeção que o diâmetro das estacas é de 30 $\mathrm{cm}$ e sua profundidade alcança os 2 metros o que está em concordância com os ensaios de resistência realizados no solo que evidenciam uma camada resistente a apenas 2 metros de profundidade.

Foram observadas diversas patologias na fundação: a primeira locação das fundações foi realizada de forma errônea, alguns blocos apresentam armadura exposta e técnica de concretagem errada. Estes erros são mostrados nas Figuras 7 a 9 .

Figura 7: Primeiras fundações locadas de forma errada.

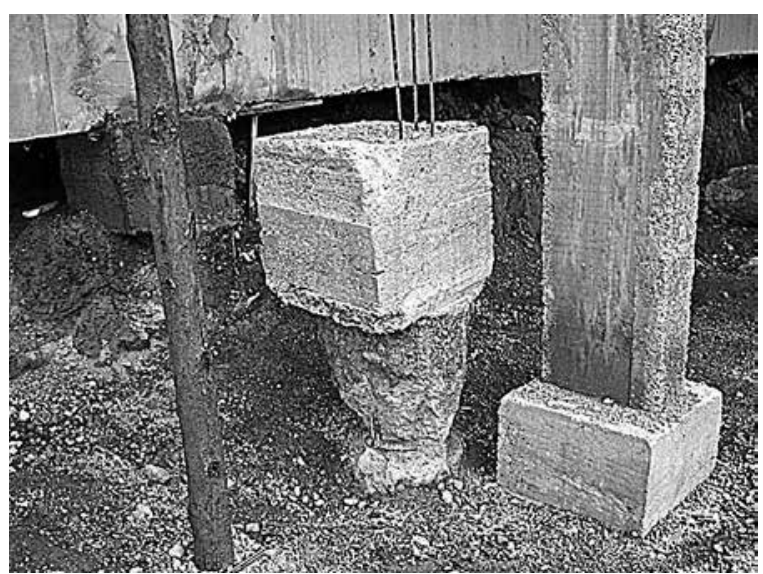

Figura 8: Fundações fora do prumo.

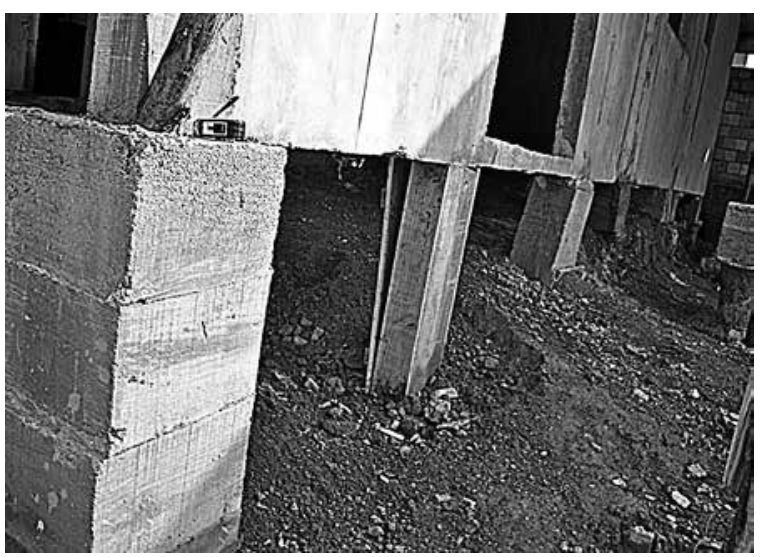


Figura 9: Fundações com armadura exposta.

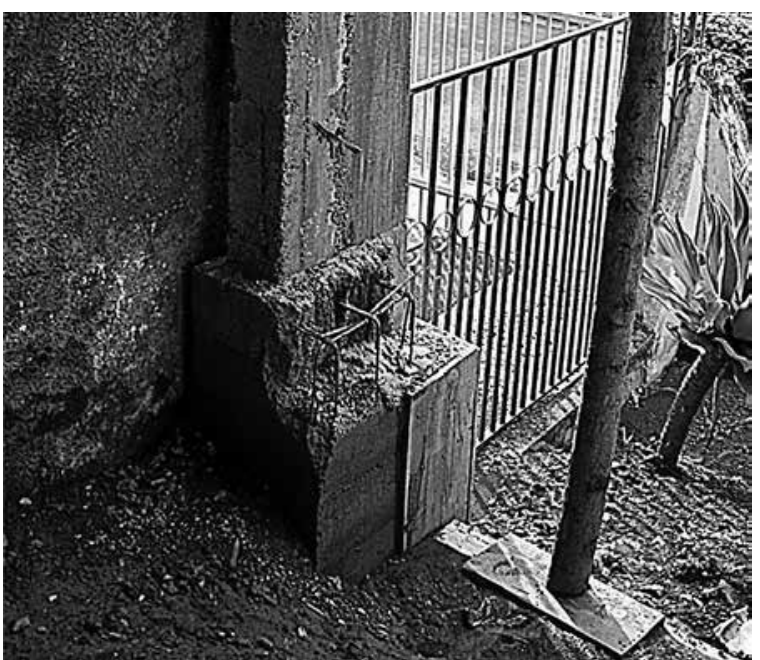

\subsubsection{Lajes}

A laje utilizada no projeto é do tipo alveolar, constituída de painéis de concreto protendido, que possuem seção transversal com altura constante e alvéolos longitudinais, responsáveis pela redução do peso da peça. Os painéis protendidos utilizados são de largura de $124,5 \mathrm{~cm}$ e altura de $12 \mathrm{~cm}$, com concreto de elevada resistência característica à compressão (fck $\geq 45 \mathrm{MPa}$ ) e aços especiais para protensão, o esquema é mostrado na Figura 10.

Figura 10: Pré-moldado para lajes.

\begin{tabular}{l|l|l}
\hline$\square 0.0 .0 .0 .0 .0 .0 .0 .0 .5$ & $\begin{array}{l}\text { Altura }=12 \mathrm{~cm} \\
\text { Peso-Próprio }=2,20 \mathrm{kN} / \mathrm{m}^{2} \\
\mathrm{I}=13.623 \mathrm{~cm} / \mathrm{m}\end{array}$ \\
\hline
\end{tabular}

O processo de montagem da laje alveolar é simples e repetitivo. Após o posicionamento sobre a estrutura, é feito o nivelamento dos painéis alveolares (equalização) com o auxílio de torniquetes de madeira para, somente depois, iniciar-se o preenchimento das juntas entre as placas com concreto fino (graute).

O preenchimento das juntas entre os painéis tem como objetivo a garantia de um funcionamento solidário das diversas placas que constituem uma laje alveolar, estabelecer uma colaboração entre elas na redistribuição de cargas das mais carregadas para as menos carregadas, além de fornecer o acabamento e a estanqueidade necessária (Figura 11).

Figura 11: Preenchimento das juntas.
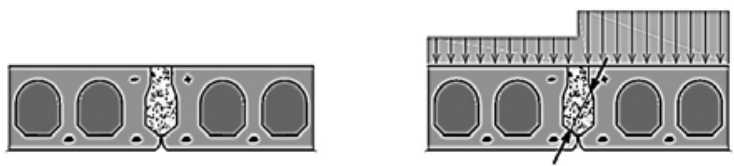

Durante a construção surgiram diversas fissuras, então, a equipe de construção colocou vigas de 9 $\mathrm{cm} \times 13 \mathrm{~cm}$, para ajudar na sustentação, porém, isto não foi suficiente, pois as vigas não estão devidamente armadas e nem ancoradas, isto é mostrado na Figura 12.

Figura 12: Vigas feitas para reforço sem ancoragem correta.

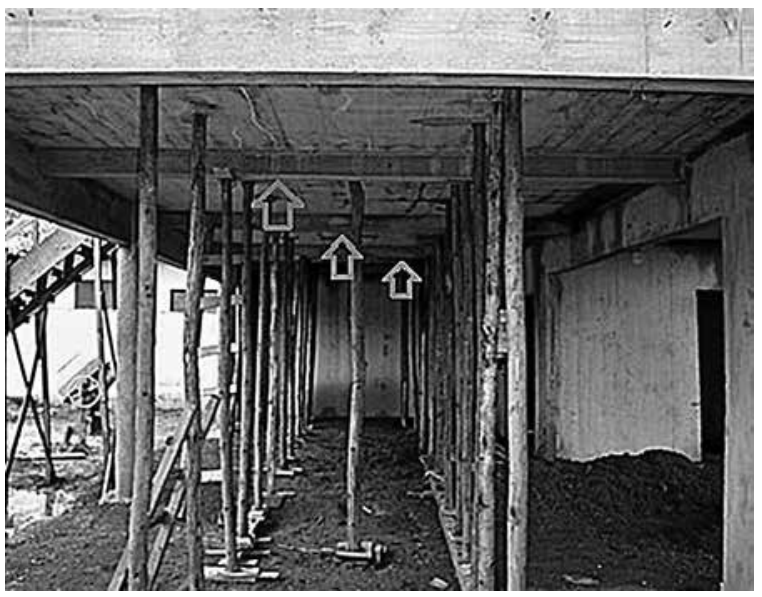

A Figura 13 mostra em planta a localização das vigas mostradas na foto anterior.

Figura 13: Localização das vigas sem ancoragem.

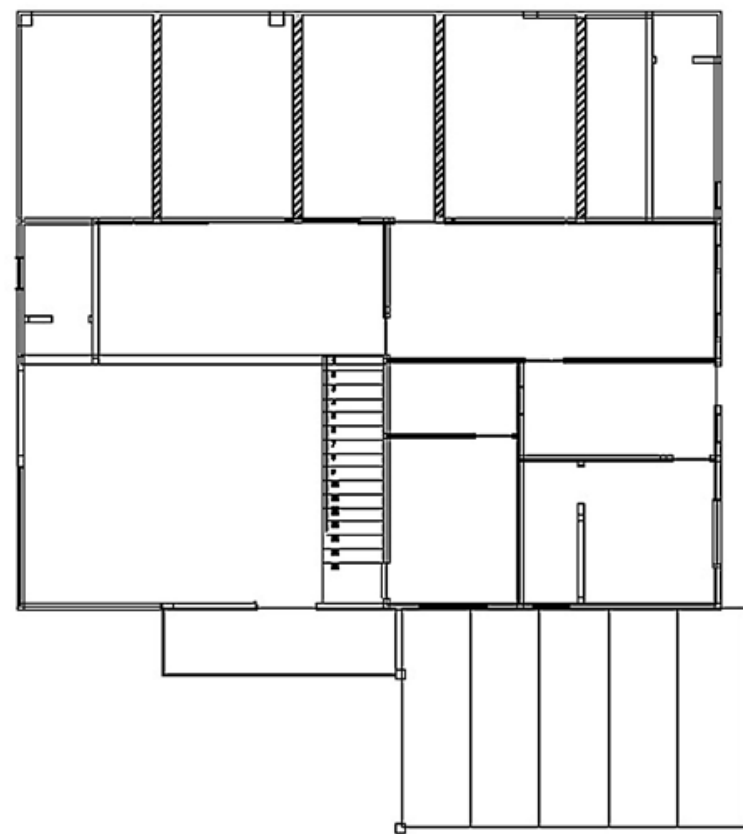

VIGAS INSERIDAS APúS APARECIMENTI DAS FISSURAS.

Algumas peças pré-moldadas apresentaram defeitos, como o aparecimento de aberturas nas lajes. 


\subsubsection{Vigas}

Mesmo que o sistema estrutural seja de alvenaria estrutural, algumas zonas da casa foram executadas usando o sistema convencional (viga pilar em concreto armado). Nestes casos as vigas apresentaram diversas fissuras causadas por diferentes fatores como: excesso de carga, falta de um arranjo de armaduras suficientes e más técnicas de construção.

Um exemplo deste problema apareceu na fachada frontal correspondente à área da garagem mostrada na Figura 14.

Figura 14: Desenho esquemático das patologias encontradas na fachada principal.

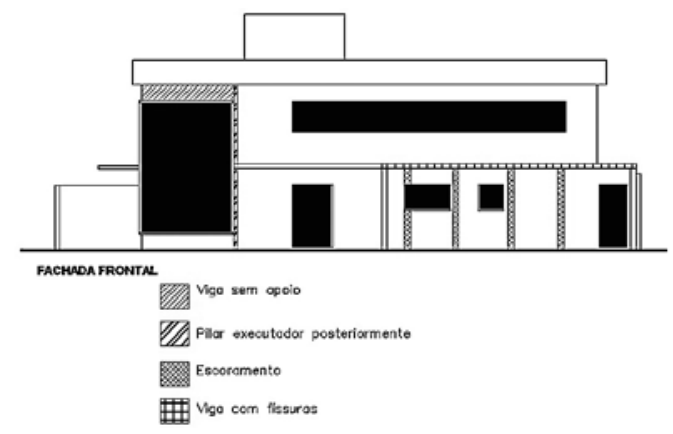

A viga da fachada frontal, apoiada em dois pilares, vence um vão de quase 9 metros. Este elemento estrutural atingiu os Estados Limites de Serviço de formação de fissuras, pois apresenta abertura de fissuras e deflexões excessivas superiores aos limites impostos na norma. A viga apresenta as fissuras clássicas causadas por solicitações de flexão, e de cisalhamento, que são mostradas na Figura 15.

Figura 15: Viga esquemática com fissuras de flexão e de cisalhamento.

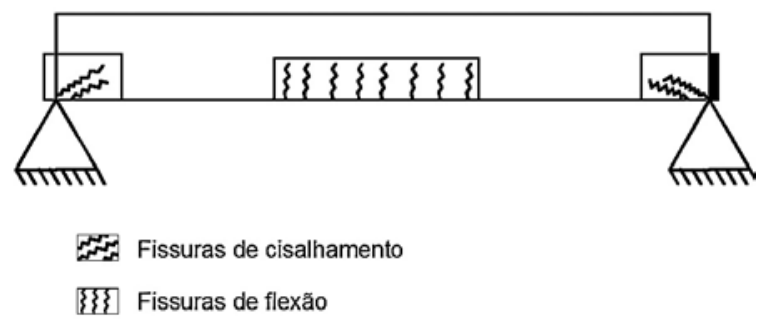

A Figura 16 mostra a viga que que apresenta as fissuras.
Figura 16: Viga que apresenta fissuras de flexão e cisalhamento.

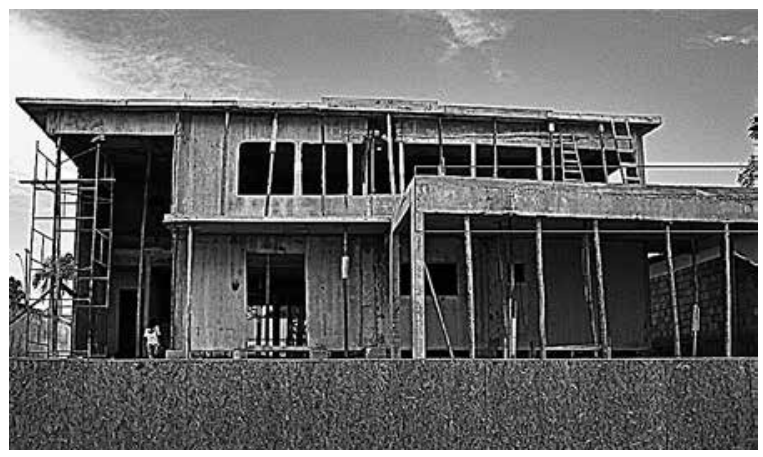

Outra viga que apresenta grandes patologias é mostrada na Figura 17, a viga sofreu fissuras de flexão devido à descontinuidade de cargas ocasionada pela ausência de pilares.

Figura 17: Localização das fissuras de flexão na viga.

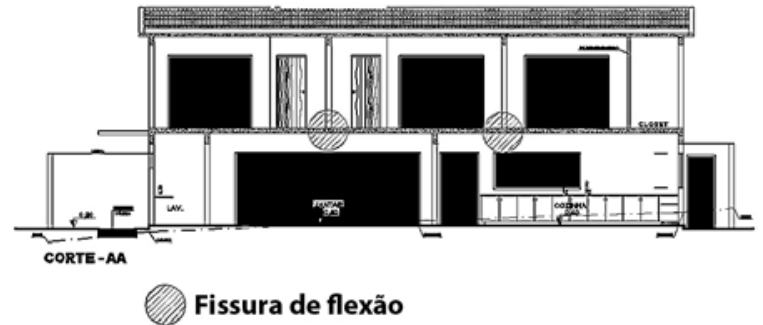

A Figura 18 mostra as fissuras presentes na viga da foto anterior.

Figura 18: Fissuras na viga.

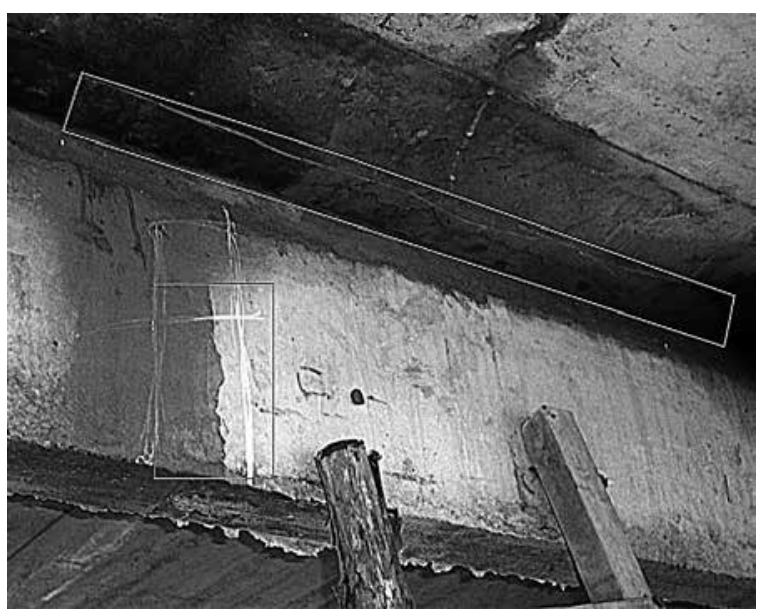

O projeto arquitetônico apresenta um pé direito duplo em uma das fachadas, isto usando uma viga balcão na cobertura (Figura 19). Esta viga que está submetida a torção não foi executada como uma viga contínua com um balanço, e sim usando uma viga pré-moldada sem ligação nem ancoragem com as vigas próximas. Deflexões significativas surgiram após a montagem. 
Figura 19: Viga balcão.

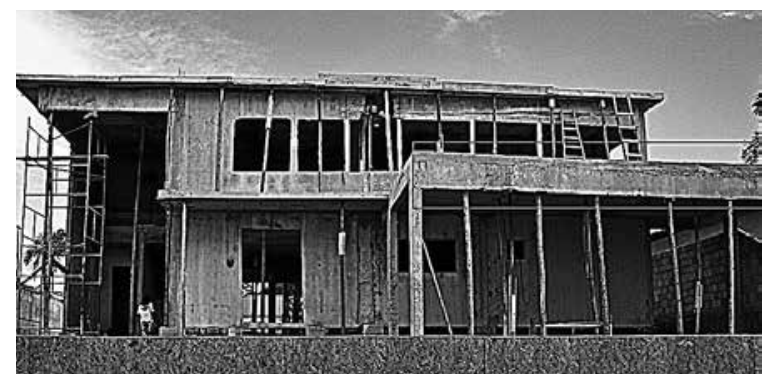

A viga que se encontra a direita da viga balcão apresenta descontinuidade na seção transversal. A viga foi interrompida deixando as armaduras expostas (Figuras 20 e 21).

Figura 20: Viga mal concretada com armadura exposta.

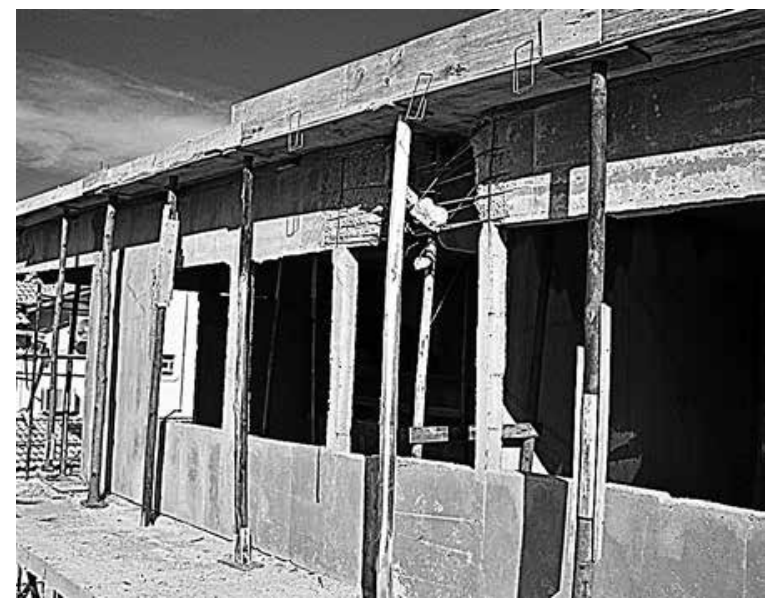

Figura 21: Detalhe da viga anterior.

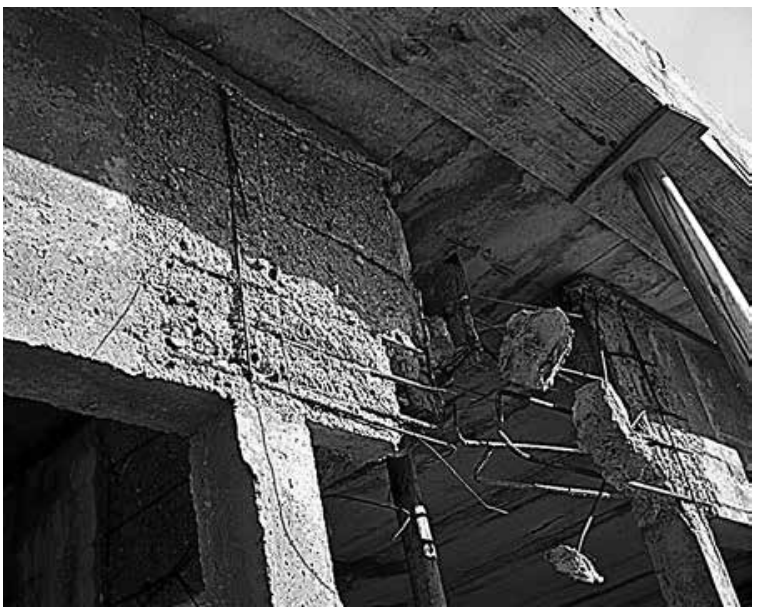

\subsubsection{Pré-moldados}

As paredes feitas em pré-moldados apresentam diversas fissuras e até mesmo aberturas, (Figuras 23 e 24).
Figura 23: Fissuras no pré-moldado destacadas com giz.

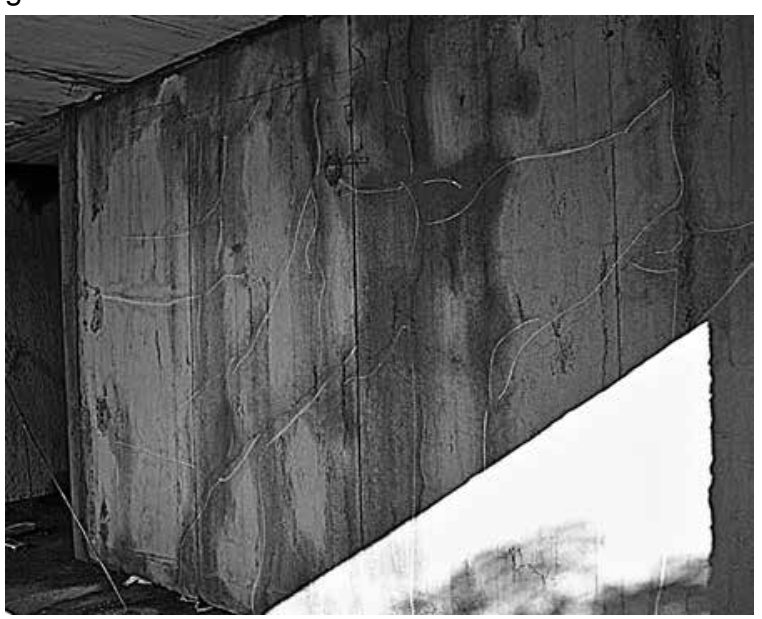

Figura 24: abertura no pré-moldado.

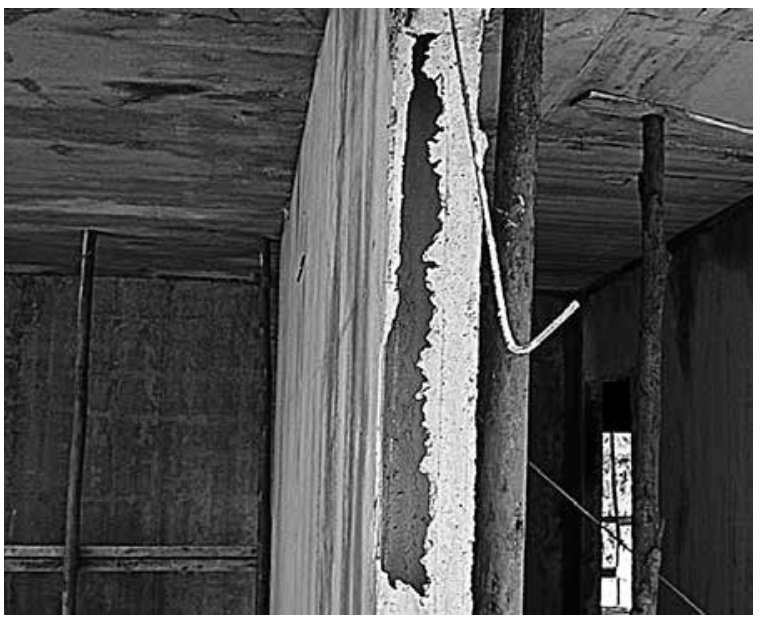

\subsubsection{Pilares}

A fachada posterior do projeto está constituída de quatro pilares ligados por vigas simplesmente apoiadas. Os pilares apresentam deslocamentos horizontais decorrente de uma má execução e é evidente a falta de armaduras que liguem as vigas e pilares. (Figura 25).

Figura 25: Pilares fora do prumo.

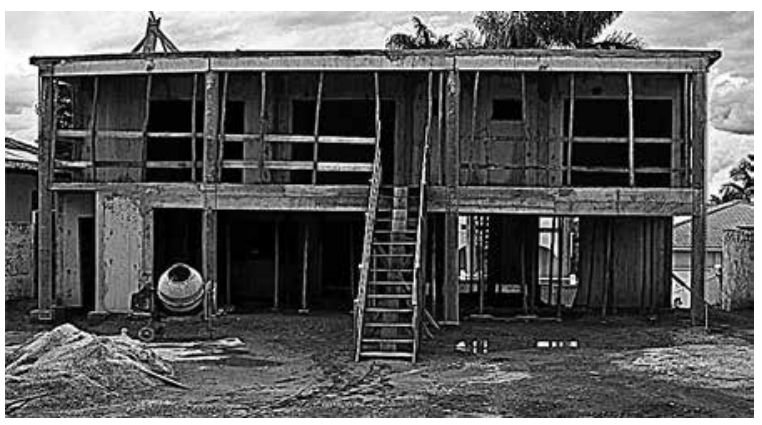

\subsection{Observações realizadas}

Em um projeto de concreto armado, é necessário que se evite a ocorrência dos Estados Limites de Serviço, aqueles relacionados à durabilidade 
das estruturas, aparência, conforto do usuário e boa utilização funcional e Estados Limites Últimos correspondentes à máxima capacidade portante da estrutura. Neste projeto foram atingidos os seguintes Estados Limites.

E.L.S :

- Estado limite de abertura das fissuras;

- Estado limite de deformações excessivas.

E.L.U.:

- Estado limite último de esgotamento da capacidade resistente da estrutura, no seu todo ou em parte, devido às solicitações normais e tangenciais;

\section{Projeto de reforço}

Para resolver os diversos problemas que surgiram nesta casa foi necessário um projeto de reforço para que a estrutura pudesse resistir os carregamentos atuantes evitando atingir os Estados Limites de Serviço.

\subsection{Estrutura de concreto armado}

Foi realizada uma marquise na fachada frontal da casa, mostrada na Figura 26.

Figura 26: Marquise na fachada frontal.

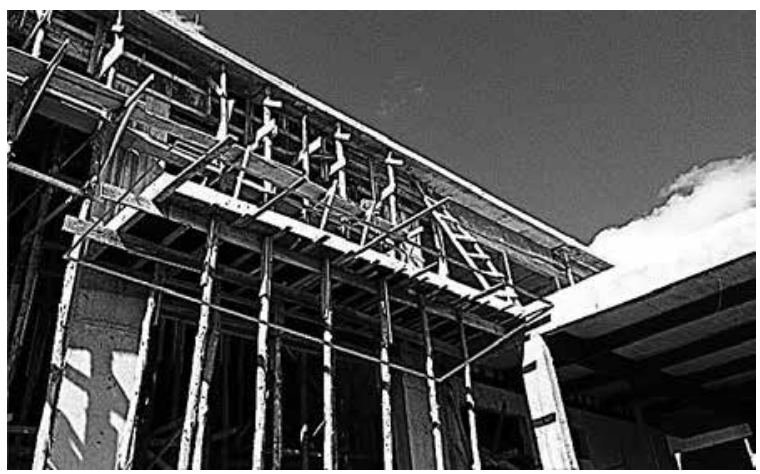

Os pilares circulares, foram reforçados com novas armaduras, colocados e novas formas e reconcretados, como mostra o esquema da Figura 27.
Figura 27: Recuperação dos pilares.

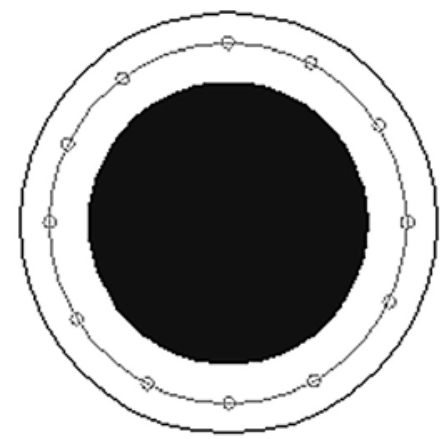

PILAR ANTIGO

ARMADURA NOVA

PILAR NOVO

\subsection{Estrutura em aço}

Para recuperar as lajes que apresentavam flechas excessivas foi instalada uma grelha metálica usando perfis laminados. (Figuras 28 e 29).

Figura 28: Reforço na laje superior.

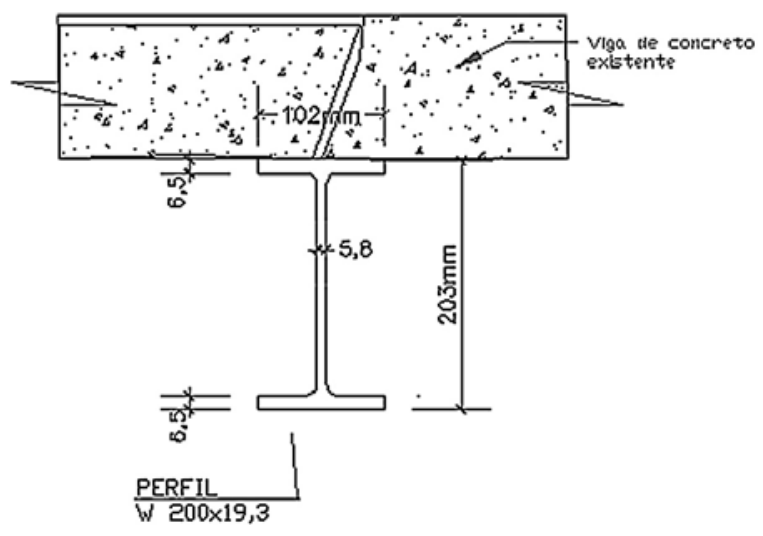

Figura 29: Vigas metálicas de perfil laminado colocadas para sustentar a laje da garagem.

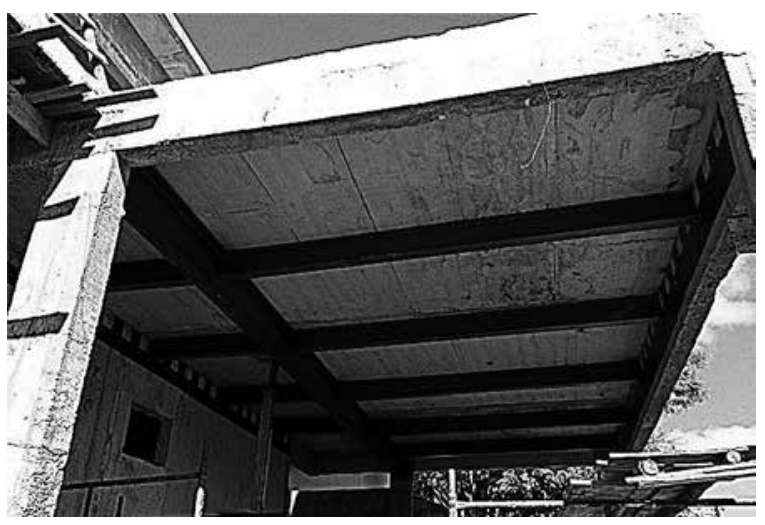


Figura 30: Vigas metálicas sendo soldadas em obra.

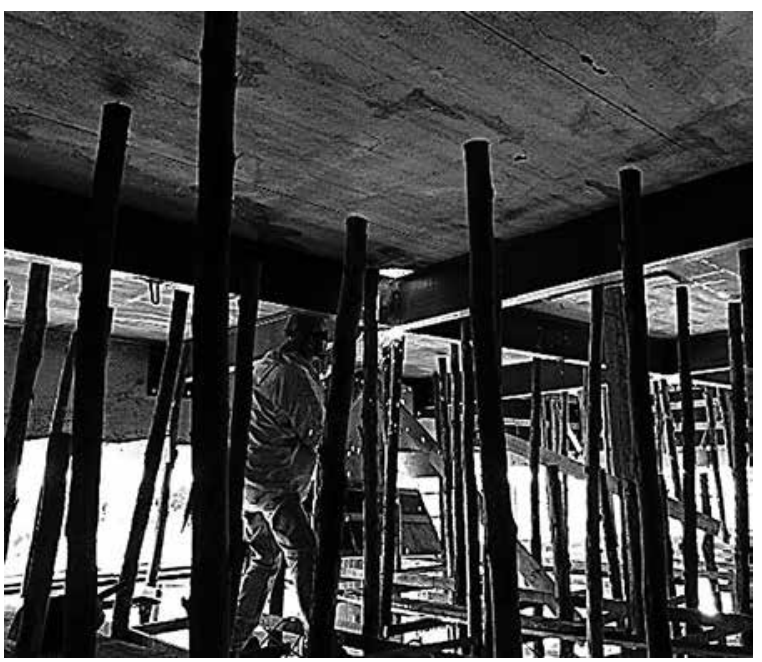

\subsection{Estruturas de chapa coladas}

Foram colocadas chapas de aço para combater o esforço de cisalhamento nas vigas, como mostrado nas Figuras 31 a 34.

Figura 31: Chapa para combater o cisalhamento na viga da fachada frontal.

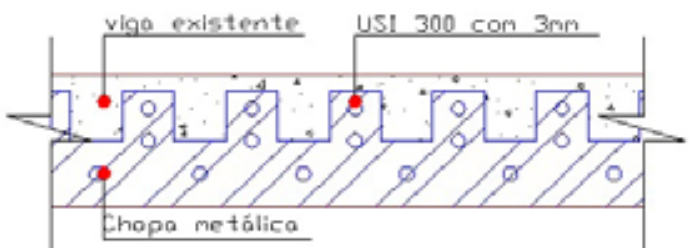

Figura 32: Chapa para combater o cisalhamento na viga da fachada frontal.

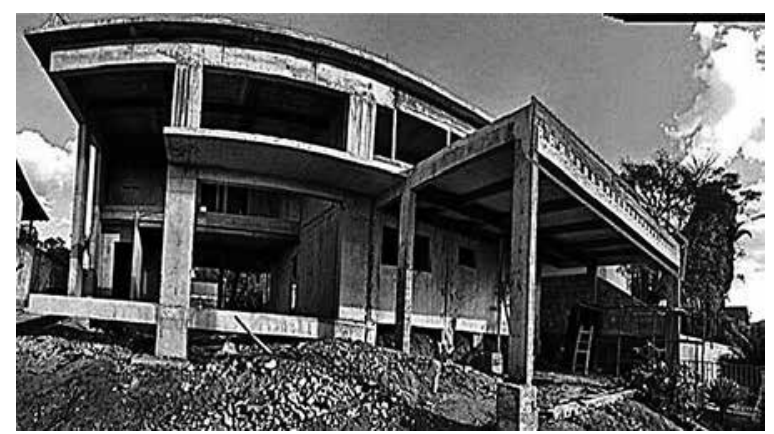

Figura 33: Chapa para combater o cisalhamento na viga da fachada posterior.

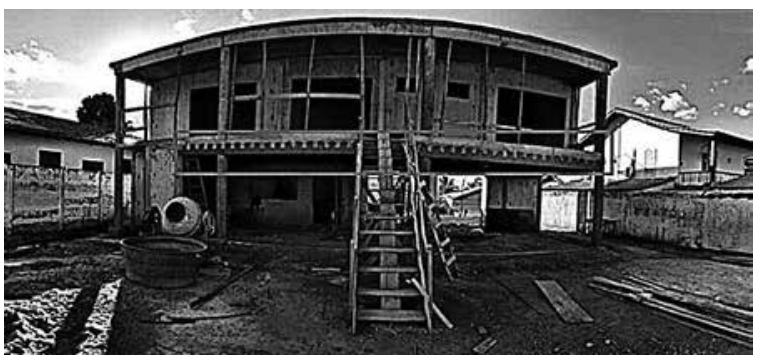

Figura 34: Chapa para combater o cisalhamento no interior da casa.

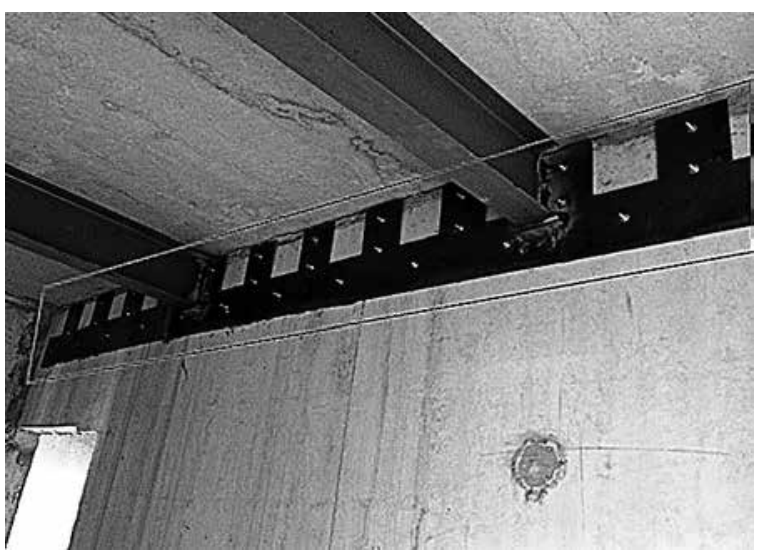

\subsection{Pré-moldados}

Já para recuperar as fissuras nos pré-moldados das paredes mostradas anteriormente, que são fissuras causadas por diversos problemas, como mostra a Figura 35, recomenda-se usar Sika Filler-100, que permite encher juntas sem movimento, fissuras e pequenos buracos em paredes interiores. Pronto para aplicar, não requer qualquer mistura e com acabamento liso.

Figura 35: Fissuras nos pré-moldados das paredes.
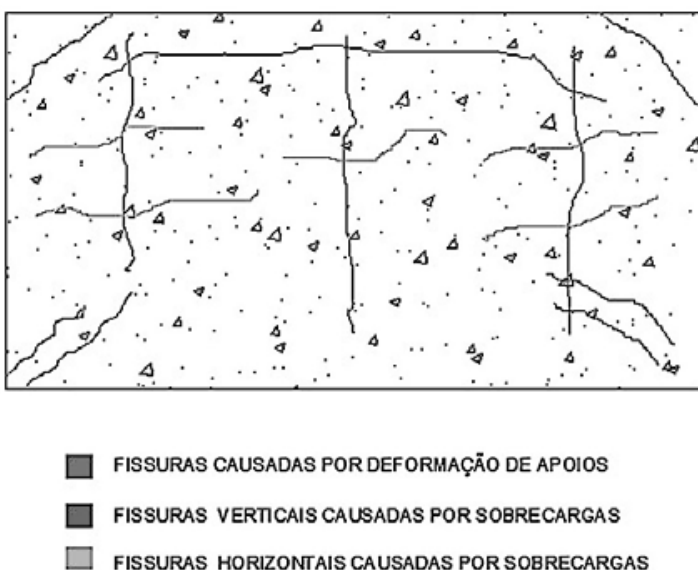

\section{Conclusão}

Atendendo ao objetivo proposto de mostrar os problemas da utilização errada de pré-moldados e a recuperação e reforço de sistema estrutural, constatou-se que a utilização de pré-moldados sem um projeto feito por um engenheiro ou alguém especializado no assunto, ao contrário de ser algo rápido, prático e barato, pode trazer vários problemas e prejuízos. Se fazendo necessário reforçar a estrutura para evitar a demolição total ou parcial da mesma. Sendo assim, conclui-se que projeto de reforço, usando vigas metálicas e chapa colada, utilizado para esta residência foi uma ótima solução para os 
problemas estruturais que surgiram no decorrer da obra, tendo em vista que conseguiu deixar a estrutura da casa estável e pronta para receber o acabamento.

\section{Referências bibliográficas}

DIMANDE, Américo Ocua. Técnicas de reforço de estruturas em betão. 2011.

SILVA, Erick Almeida. Técnicas de recuperação e reforço de estruturas de concreto armado. São Paulo: Universidade Anhembi Morumbi, 2006.

CAMPOS, Luiz Eduardo Teixeira. Técnicas de recuperação e reforço estrutural com estruturas de aço. Rio de Janeiro: UERJ, 2006.

ARAÚJO, Caroline Maia. Reforço de vigas de concreto à flexão e ao cisalhamento com tecidos de fibra de carbono. Rio de Janeiro: UFRJ, 2002.

BEBER, Andriei José. Comportamento Estrutural de Vigas de Concreto Armado reforçadas com Compósitos de Fibra de Carbono. Porto Alegre: UFRS, 2003.

PEREIRA, Bianca Salomão Contardo Silvino. Estudo de reforço externo à força cortante em vigas de concreto armado. Rio de Janeiro: PUC , 2005.

FILHO, Marcello Varella Souto. Modelagem numérica de reforço estrutural em vigas de concreto armado. Rio de Janeiro: PUC, 2003.

ALMEIDA, Sandra Freire de. Análise experimental estática e dinâmica da rigidez de ligações vigapilar de concreto. São Paulo: EESC, 2010.

PEREIRA, Fábio Sérgio da Costa. Reforço de estrutura de concreto armado. 2011.

FERRARI, Vladimir José; PADARATZ, Ivo José. Reforço à flexão em vigas de concreto armado com manta de fibra de carbono: mecanismos de incrementos de ancoragem. Santa Catarina: UFSC, 2002.

KLEIN, Tana Renck. Reforço estrutural em estrutura em concreto armado. Rio Grande do Sul: UFRGS, 2012.

TISOT, Guilherme di Domenico. Reforço à flexão de vigas de concreto armado submetidas a carregamento precoce. Rio Grande do Sul: UPF, 2010.

PIMENTA, Taia Marinho. Comportamento estrutural de vigas de concreto armado reforçadas com chapas metálicas, coladas com geopolímero, e com mantas de sisal coladas com resina epóxi. Paraíba: UFPB, 2012. 
